\title{
Supported catalysts for induction-heated steam reforming of methane
}

\section{Scarfiello ${ }^{\text {a,1 }}$, M. Bellusci ${ }^{\text {a }}$, L. Pilloni ${ }^{\text {a }}$, D. Pietrogiacomi ${ }^{\text {b }}$, A. La Barbera $^{\text {a }}$, F. Varsano ${ }^{a,}{ }^{*}$}

a ENEA, Casaccia Research Centre, Via Anguillarese 301, Roma, 00123, Italy

${ }^{\mathrm{b}}$ Chemistry Department, Sapienza University of Rome, P.le A. Moro, 5, Rome, 00185,

Italy

\begin{abstract}
A B S T R A C T
$\mathrm{Ni}_{60} \mathrm{Co}_{40}$ nanoparticles supported on $\gamma-\mathrm{Al}_{2} \mathrm{O}_{3}$ capable of simultaneously catalysing the steam reforming reaction of methane and supplying in-situ the heat necessary to activate the reaction by induction heating, have been synthesized and characterized. Energy is remotely and promptly supplied by an alternating radiofrequency magnetic field (induction heating system) to supported nanoparticles that act as dissipating agents by virtue of their ferromagnetic properties. The temperature reached on the Ni-Co based catalyst surface is high enough to obtain good catalytic performances for the steam methane reforming (SMR). By varying synthesis conditions, samples with two different metal loading (17 wt\% and $30 \mathrm{wt} \%$ ) and different particle size distribution were prepared and characterized. Experimental results evidence that the temperature reached on the catalyst surface is related to the metal loading and to the particles size distribution that strongly affect the ability of ferromagnetic nanoparticles to convert the externally applied radio frequency field into heat. Catalyst pellets proved their effectiveness reaching the temperature of $720{ }^{\circ} \mathrm{C}$ during SMR reaction and $80 \%$ methane conversion.
\end{abstract}

Keywords:

Induction heating

Magnetic catalysis

Steam reforming

Ferromagnetic nanoparticles

* Corresponding author.

E-mail address: francesca.varsano@enea.it (F. Varsano).

${ }^{1}$ Current Affiliations: a) Université de Toulouse, IMT Mines Albi, UMR CNRS 5302, Centre RAPSODEE, Campus Jarlard, 81,013 Albi, cedex 09 (France); b) LPCNO, Université de Toulouse, CNRS, INSA, UPS 135 avenue de Rangueil, 31,077 Toulouse (France); c) LCC, CNRSUPR 8241, ENSIACET Universite' de Toulouse (France). 


\section{Introduction}

Magnetic nanoparticles immersed in an alternating electromagnetic field dissipate energy, generating heat [1-4]. The exploitation of this heat for the purpose of energetically feeding chemical reactions is a novelty and has the potential to be a revolutionary technique in the construction of highly energy-efficient reactors [5-12]. In fact, the ability of radiofrequency induction to transfer energy directly to the material to be heated (catalytic bed), thanks to the selective absorption of energy by magnetic materials, allows to supply heat exclusively at the solid phase catalysing the reaction, leaving the feeding fluid mass and the reactor walls relatively cold. In contrast to conventional heating where heat is delivered from the outside to the inside of the reactor, induction heating generates heat right where is needed overcoming an important limit of the heating systems currently in use, where impressive thermal gradients between the reactor walls and the heart of the catalytic bed are observed. Furthermore, induction heating promotes process intensification since the non-catalysed parasitic reactions, however activated by temperature, are considerably reduced. With the instantaneous generation of localized heat directly or nearby the chemically active site, in principle it is possible to supply only the energy necessary to induce the catalytic reaction, considerably reducing heat dissipation and waste of material and energy with significant advantages in terms of efficiency of production processes.

Moreover, the heating rate can reach hundreds of degrees per minute allowing rapid reactor heating and shutdown. This has enormous advantages in terms of process security, allowing greater control in exothermic processes. An additional innovative aspect is that the high heating rate reached by magnetic induction offers the great opportunity to couple endothermic processes to discontinuous energy sources. The possibility of activating chemical reactions "on-demand" has recently attracted a great interest and several examples of induction heated, or microwave heated, chemical processes have been proposed [13-21].

While on the one hand the possibility of transferring contactless heat to the catalyst is very attractive because it immediately suggests energy savings, on the other hand the generation of an RF field is an expensive process that requires the use of electricity. Almind et al. have recently reported considerations on the energy transfer efficiency [22] for the steam methane reforming powered by induction. They developed a model that extrapolating lab scale experimental data to large systems predicted energy efficiency above $80 \%$, allowing the technology to be competitive with other elec-tricity driven routes to hydrogen production.

In our previous research, a mixed metal catalyst with the $\mathrm{Ni}_{60} \mathrm{Co}_{40}$ (mole ratio) composition has been developed for the dry reforming of methane. The catalyst, consisting in nickelcobalt alloy powders activated by milling, is able at the same time to catalyse the chemical process and deliver the heat necessary to run the endothermic reaction, reaching $900{ }^{\circ} \mathrm{C}$ when heated by induction $[23,24]$. For such material, considering the micrometric size of the particles, the heating mechanism was predominantly due to eddy currents induced on the surface of metallic powders. The catalyst proved to be active and initial stability tests were encouraging. On the other hand, the use of metal powders as such is uneconomical since, being the catalyst specific surface area very low, the overall catalytic activity is rather poor.

With the intention of preparing a more performing catalyst, we synthesized $\mathrm{Ni}_{60} \mathrm{Co}_{40}$ supported nanoparticles having a higher specific surface area of the active phase with respect to that of unsupported metal particles. However, unlike what has been observed for the nickel cobalt alloy micrometric powders [24], for ferromagnetic nanoparticles the dominant energy dissipation mechanism causing heat generation is unlikely to be attributable to eddy currents but will mainly be related to magnetic hysteresis and relaxation losses [2,25]. For this class of materials the particle size can significantly influence the heating properties $[26,27]$. Therefore, to achieve an appropriate temperature and an adequate energy load to feed the process, it is desirable to optimize the synthesis of the magnetic particles. For this purpose, an impregnation method was adopted using commercial $\gamma-\mathrm{Al}_{2} \mathrm{O}_{3}$ catalyst support and $\mathrm{Ni}_{60} \mathrm{Co}_{40}$ metallic nanoparticles were grown by changing synthesis parameters.

The steam methane reforming reaction [28] was selected as a model reaction to test the performances of the prepared samples because most of the industrial hydrogen demand is satisfied by the implementation of this highly endothermic process $\left(\Delta \mathrm{H}^{\circ}=206 \mathrm{~kJ} \mathrm{~mol}^{-1}\right)$.

The process is usually described by Eq. (1), often accompanied by competing or side reactions such as the water gas shift (2), the methane cracking (3) or carbon gasification (4), whose occurrence depends on process conditions:

$$
\begin{aligned}
& \mathrm{CH}_{4}+\mathrm{H}_{2} \mathrm{O}=\mathrm{CO}+3 \mathrm{H}_{2} \\
& \mathrm{CO}+\mathrm{H}_{2} \mathrm{O}=\mathrm{CO}_{2}+\mathrm{H}_{2} \\
& \mathrm{CH}_{4}=\mathrm{C}+2 \mathrm{H}_{2}
\end{aligned}
$$


$\mathrm{C}+\mathrm{H}_{2} \mathrm{O}=\mathrm{CO}+\mathrm{H}_{2}$

The majority of industrial catalysts $[29,30]$ are based on nickel, although many catalysts being researched now have better performance at laboratory scale $[31,32]$.

In industrial reformers, heat transfer from the furnace to the catalyst bed is considered the source of principal energy waste [33-36] and an elaborate heat exchange network is utilized to increase the process efficiency. In this sense, induction heating could provide a useful solution, delivering heat in remote right where is needed and reducing losses.

In the following, we report the preparation of $\mathrm{Ni}_{60} \mathrm{CO}_{40}$ nanoparticles supported on commercial $\gamma-\mathrm{Al}_{2} \mathrm{O}_{3}$ pellets under different synthetic conditions (metal loading and calcination temperature) and their performance toward the steam methane reforming reaction powered by induction heating. The results obtained from the physical-chemical characterization on the metal alloy particles are combined with their heating performances to discuss the effect on the catalytic activity.

\section{Materials and methods}

\section{Catalyst preparation and characterization}

Catalysts are prepared using cylindrical $\left(1 / 8^{\prime \prime}\right)$ pellets of $\gamma$ $\mathrm{Al}_{2} \mathrm{O}_{3}$ (Alfa Aesar) as a support. Support specific surface area is $250 \mathrm{~m}^{2} \mathrm{~g}^{-1}$. Catalysts have been prepared by equi-librium adsorption [37], dipping alumina pellets (batches of 180 pellets) in a $\mathrm{Ni}\left(\mathrm{NO}_{3}\right)_{2} * 6 \mathrm{H}_{2} \mathrm{O}$ (Merck-EMSURE) and $\mathrm{Co}\left(\mathrm{NO}_{3}\right)_{2} * 6 \mathrm{H}_{2} \mathrm{O}$ (Merck-EMSURE) aqueous solution at room temperature and stirring the solution overnight. Two solutions having different total concentration, $4 \mathrm{M}$ and $8 \mathrm{M}$ respectively, with the same $\mathrm{Ni}$ :Co ratio were prepared. Excess solution was then removed and the samples were dried at 80 ${ }^{\circ} \mathrm{C}$ overnight. The as prepared samples, loaded with metal precursors, were subjected to a calcination treatment to remove the nitrates in air flow $\left(50 \mathrm{~mL} \mathrm{~min}^{-1}\right.$ ) inside a horizontal tubular furnace (Carbolite) for $1 \mathrm{~h}$. Three different calcination temperatures, i.e. $450^{\circ} \mathrm{C}, 600^{\circ} \mathrm{C}$ and

$750{ }^{\circ} \mathrm{C}$ were used to evaluate their effect on the metal particle size, their distribution and ultimately on the cata-lytic activity. One hour was sufficient for the precursor complete elimination. Few samples were stored in glass desiccator before calcination ( 6 months) and in the manu-script are labeled as "aged". One sample was calcined in a static air atmosphere (see Table 1). Finally, the pellets were reduced by Temperature Programmed Reduction technique (TPR) in $\mathrm{Ar}-\mathrm{H}_{2}$ (3\%vol.) flow $\left(50 \mathrm{~mL} \mathrm{~min}^{-1}\right)$ with a heating

rate of $10{ }^{\circ} \mathrm{C} \mathrm{min} \mathrm{min}^{-1}$ at $900{ }^{\circ} \mathrm{C}$ and maintaining the temperature for $5 \mathrm{~h}$ using a Micromeritics Autochem II 2920. Samples are labeled as NiCoxY, were $\mathrm{x}$ stands for the metal total loading and $\mathrm{Y}$ for the calcination temperature.

Atomic Absorption Spectroscopy (AAS) (Varian Spectra AA220) was utilized to evaluate the amount of metal in the sample.

X-ray diffraction (XRD) analyses were carried on powders (pellets are easily grinded in a mortar) employing a diffractometer equipped with a 120 linear simultaneous detector
Table.1 List of prepared samples. Effect of synthesis conditions on particle size.

\begin{tabular}{|c|c|c|c|c|}
\hline Sample & $\begin{array}{c}\text { Me (wt } \\
\%)\end{array}$ & $\begin{array}{c}\text { T calc } \\
\left({ }^{\circ} \mathrm{C}\right)\end{array}$ & $\begin{array}{c}\text { Cristallite size }{ }^{a} \\
(\mathrm{~nm})\end{array}$ & $\begin{array}{c}\text { Particle size } \\
\text { (nm) }\end{array}$ \\
\hline $\mathrm{NiCO}_{17} 450$ & 17 & 450 & $7 \pm 1$ & $9 \pm 2$ \\
\hline $\mathrm{NiCo}_{17} 600$ & 17 & 600 & $9 \pm 2$ & $10 \pm 2$ \\
\hline $\mathrm{NiCo}_{17} 600^{*}$ & 17 & 600 & $20 \pm 2$ & $23 \pm 5$ \\
\hline $\mathrm{NiCo}_{17} 750$ & 17 & 750 & $24 \pm 3$ & $29 \pm 5$ \\
\hline $\mathrm{NiCo}_{17} 750 *$ & 17 & 750 & $28 \pm 2$ & $29 \pm 5$ \\
\hline $\mathrm{NiCO}_{30} 450 *$ & 30 & 450 & $32 \pm 1$ & $38 \pm 9$ \\
\hline $\mathrm{NiCo}_{30} 600$ & 30 & 600 & $19 \pm 2$ & $18 \pm 5$ \\
\hline $\mathrm{NiCO}_{30} 600 *$ & 30 & 600 & $25 \pm 2$ & $23 \pm 5$ \\
\hline $\mathrm{NiCO}_{30} 600^{* *}$ & 30 & 600 & $80 \pm 2$ & $52 \pm 15$ \\
\hline $\mathrm{NiCO}_{30} 750$ & 30 & 750 & $45 \pm 2$ & $35 \pm 12$ \\
\hline
\end{tabular}

${ }^{a}$ By XRD Analysis applying the Debye-Scherrer equation.

b By SEM Analysis, applying the Lognormal size distribution curve to size distribution histograms; statistical analysis from over 400 particles.

* Sample aged in glass desiccator before calcination (6 months).

** Calcination in static atmosphere (air).

from INEL and a monochromatized Fe $\mathrm{K}_{\alpha 1}$ source (Italstructure X-RED300).

The morphology of the catalyst pellets has been investigated by Scanning Electron Microscopy (SEM) using a highresolution microscope HRSEM LEO130. Measurements were performed on both external and internal surface of the pellets, cleaving the sample into several pieces. To highlight the presence of the metallic phase dispersed on the alumina substrate, images were collected using a RBSD (backscatter) detector. To gain information on metal particles size and its distribution SEM images were processed by Image [38] software. Size distribution histograms were fitted using a lognormal distribution function and evaluated Median particles diameters are reported. Specific surface area was evaluated by nitrogen adsorption at $77 \mathrm{~K}$ (BET method) [39] utilizing a Quantachrome NOVA 2200 apparatus.

\section{Induction heating setup}

Functional tests have been performed utilizing the catalysis flow line equipment schematized in Fig. 1 . The core of the line is a tubular quartz reactor (internal diameter $2 \mathrm{~cm}$ ) where the catalyst pellets are placed inside and held in place by a quartz frit. Typically, 18 catalyst pellets (about $0.5 \mathrm{~g}$ ) positioned to form a single layer on the frit are used. An induction coil is positioned around the tube and the samples occupy the center of the coil to make the most of the magnetic field. An Ambrell EasyHeat 2.4 induction apparatus has been utilized to heat the catalysts. The heating module (work head) is connected by r. f. cables to the power supply, allowing an easy positioning of the coil around the reactor. The coil can be adjusted to have the samples positioned at its center. The apparatus can deliver a maximum power of $2 \mathrm{~kW}$ and operates in the $150-450 \mathrm{kHz}$ frequency range. In this work, an 8 turns inductor coil of $2.5 \mathrm{~cm}$ diameter and $4.5 \mathrm{~cm}$ high working at $190 \mathrm{kHz}$ is utilized. Power consumption versus generated magnetic field is re-ported in Ref. [23] for the empty coil, the linear response being 


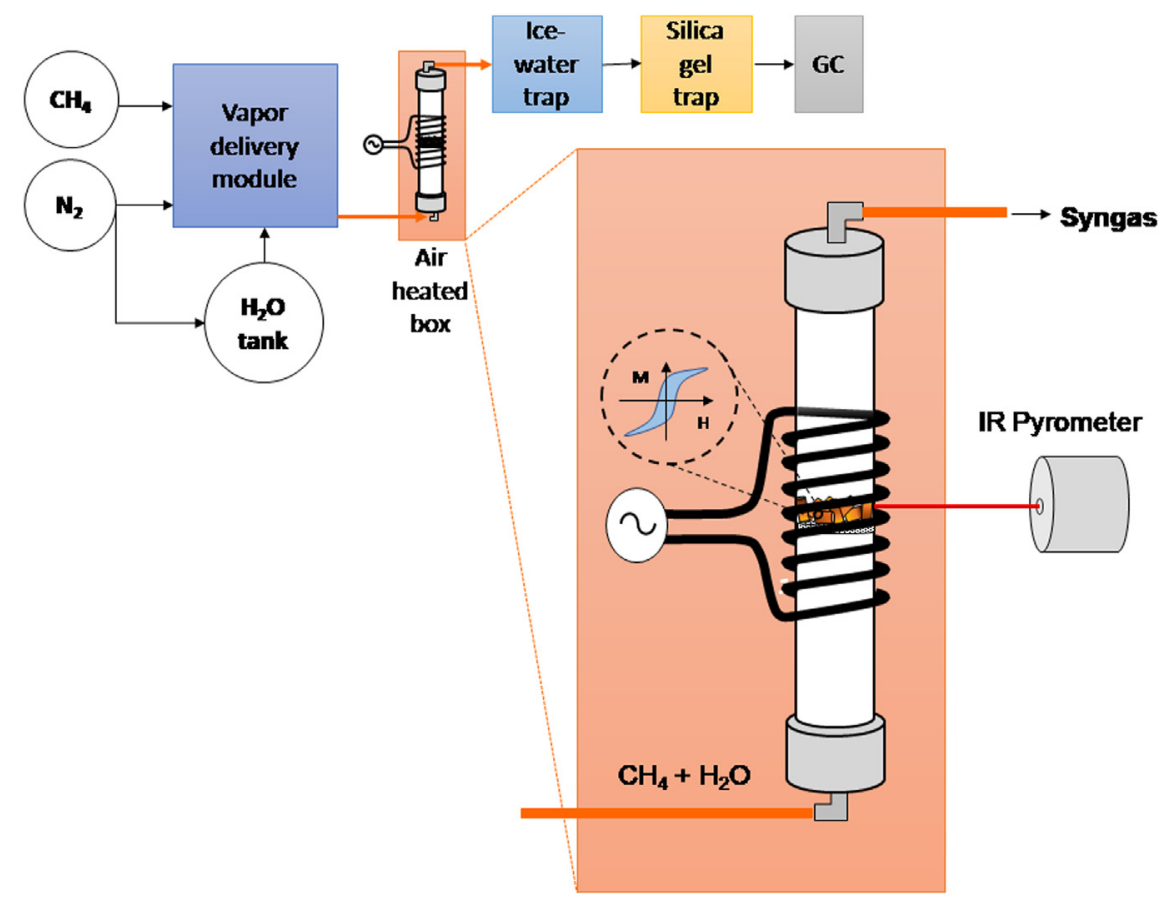

Fig.1 Outline of the catalyst testing line. Liquid water is vaporized inside a Vapour Delivery Module and conveyed to the reactor through heated lines. To prevent water condensation, the induction-heated reactor is placed inside an air-heated box. Typically, 18 catalyst pellets are utilized and placed in the same relative position within the coil. An IR pyrometer, positioned $15 \mathrm{~cm}$ from the catalyst, continuously measures the value of the average surface temperature of the catalyst (laser beam diameter $0.5 \mathrm{~mm}$ ).

limited to $35 \mathrm{mT}$. The use of 18 pellets inside the inductor does not change the power consumed appreciably. Field values are calculated based on the current applied to the inductor. All catalytic activity measurements were performed at $49.1 \mathrm{mT}$. Although from an energy efficiency point of view it would have been more convenient to work within $35 \mathrm{mT}$ range [23], it was a priority to clarify the limits of the material in terms of maximum obtainable temperatures and conversions rather than to optimize the energy transfer efficiency.

The temperature was measured continuously by focusing an IR pyrometer (IRTech Radiamatic IR20CF2150) on the surface of the pellets setting an emissivity value equal to 0.9. In this way the pyrometer provides the temperature of the catalyst positioned at the external reactor surface. It is reasonable to deduce that inner pellets may experience a higher temperature. A mixture of water vapour and methane (always in the ratio 2:1, balanced with $\mathrm{N}_{2}$ ), are conveyed to the reactor by a Vapour Delivery Module (VDM) (Bronkhorst), setting different flows. Gas Hourly Space Velocity (GHSV) values reported in the text are calculated on the basis of the geometrical volume occupied by catalyst pellets.

To avoid water condensation, the lines connecting the VDM to the reactor are heated at $110{ }^{\circ} \mathrm{C}$ by Omegalux rope heaters. For the same reason, the quartz reactor is placed inside an air-heated box $\left(110{ }^{\circ} \mathrm{C}\right)$ thus avoiding the reflux of water.

Two traps in series (a water/ice trap and a silica gel one) condense un-reacted water to prevent it from reaching the gas chromatograph. The composition of reactant and product gas mixtures was analysed by a gas chromatograph Agilent GC490 equipped with two independent columns (MS5A and Plot-U).

The conversion of methane $\mathrm{X}_{\mathrm{CH} 4}$ is calculated by Eq. (5):

$\mathrm{X}_{\mathrm{CH}_{4}}=100 * \frac{F_{\text {tot }}^{\text {in }} * \mathrm{CH}_{4}^{\text {in }}-F_{\text {tot }}^{\text {out }} * \mathrm{CH}_{4}^{\text {out }}}{\mathrm{F}_{\text {tot }}^{\text {in }} * \mathrm{CH}_{4}^{\text {in }}}$

where $F_{\text {tot }}^{\text {in }}$ is the total inlet flow, $F_{\text {tot }}^{\text {out }}$ is the total outlet flow; $\mathrm{CH}_{4}^{\text {in }}$ and $\mathrm{CH}_{4}^{\text {out }}$ are the inlet or outlet volume fraction measured by the gas chromatograph.

The primary energy used by the inductor and transformed into chemical energy is reported in terms of energy transfer efficiency of the system. This value (equation (6)) has been calculated as the ratio between the energy consumed by the reaction (per unit time), i.e. the enthalpy content of the mixture leaving the reactor subtracted from the enthalpy content of the gas entering the reactor, and the power needed to generate the magnetic field [22]. Enthalpy content at the experimental temperature has been determined on the basis of thermodynamic data [40] and the experimental mixture molar fraction:

$\boldsymbol{\eta}=\frac{P_{\text {reaction }}}{P_{\text {input }}}$

where $P_{\text {reaction }}$ has been evaluated according to

$\mathrm{P}_{\text {reaction }}=\sum_{i} H_{i} * F_{i}$ 
where $H_{i}$ is enthalpy content of $i$ 'th compound and $F_{i}$ is its flow inside (negative) or outside (positive) the reactor. The induction apparatus displays the value of the input power ( $\mathrm{P}_{\text {input }}$ ) once the operator sets the current flowing through the coil.

\section{Results and discussion}

\section{Catalyst characterization}

In order to dissipate heat in the presence of an alternating magnetic field, catalyst nanoparticles must preserve their ferromagnetic properties at the reforming operating temperature $\left(\mathrm{T}>700^{\circ} \mathrm{C}\right)$. Nickel alone, although a perfect catalyst for reforming reactions, has a Curie temperature Tc (temperature at which a transition between the ferromagnetic and paramagnetic phases occurs) equal to $354^{\circ} \mathrm{C}$, way below the process requirements. Addition of cobalt $\left(\mathrm{T}_{\mathrm{C}}=1121^{\circ} \mathrm{C}\right)$ to nickel in the selected composition $\left(\mathrm{Ni}_{60} \mathrm{Co}_{40}\right)$ raises $\mathrm{T}_{\mathrm{C}}$ value to $\sim 780$ ${ }^{\circ} \mathrm{C}$ [ 41], preserving at the same time catalytic activity toward the selected process $[9,42,43]$.

Since the amount of generated heat is dependent, among other parameters, on the amount of dissipating agent, catalyst with considerable metal loading are required. In fact, for this class of materials the metal alloy particles have a dual task, acting as catalysts for the chosen reaction and as heat suppliers to reach the appropriate temperatures.

The list of produced samples is shown in Table 1 . The results of AAS showed that two batches with a total metal loading of about 17 and $30 \mathrm{wt} \%$ respectively were obtained, with a metal ratio equal to the nominal composition (60:40) of the solution adopted for the catalyst preparation.

An example of nitrogen adsorption/desorption isotherm is reported in Fig. 2 for two samples, both calcined at $750{ }^{\circ} \mathrm{C}$ and subsequently reduced, having two different metal loadings.

Nitrogen adsorption isotherms of all prepared samples exhibit a type-IV (IUPAC) shape typical of mesoporous solids

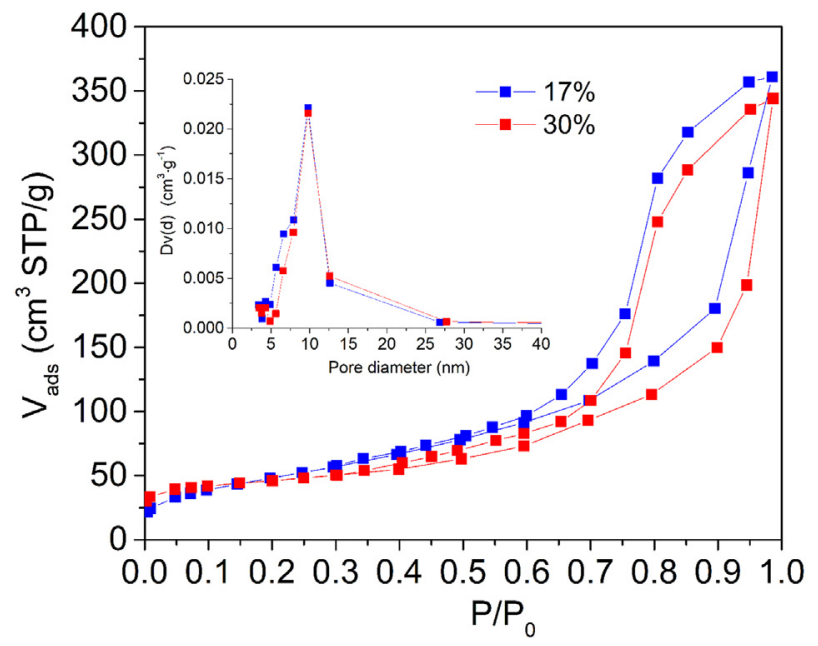

Fig.2 Nitrogen adsorption/desorption isotherms recorded at $77 \mathrm{~K}$ for two samples (calcination temperature $750{ }^{\circ} \mathrm{C}$, reduction temperature $900{ }^{\circ} \mathrm{C}$ ) with different metal loading, $17 \%$ and $30 \%$ $\left(\mathrm{NiCo}_{17} 750, \mathrm{NiCo}_{30} 750\right)$. characterized by a large uptake and a wide hysteresis at high partial pressure, explainable with the presence of a large mesoporous volume typical of the alumina substrate. Small differences between the two curves reported in Fig. 2 for the $17 \mathrm{wt} \%$ and $30 \mathrm{wt} \% \mathrm{Ni}_{60} \mathrm{Co}_{40}$ supported catalysts are likely due to minor differences in the porosity distribution. The inset in Fig. 2 shows the pores size distribution curve in the mesoporous region evaluated by the $\mathrm{BJH}$ analysis [44]. Both samples show a relatively narrow distribution curve, a maximum in the porosity distribution centered on $10 \mathrm{~nm}$ and small differences for smaller diameter. The BET surface area of the $\gamma$ $\mathrm{Al}_{2} \mathrm{O}_{3}$ support was $250 \mathrm{~m}^{2} \mathrm{~g}^{-1}$ and drops to $190 \mathrm{~m}^{2} \mathrm{~g}^{-1}$ after the 5 $\mathrm{h}$ thermal treatment at $900{ }^{\circ} \mathrm{C}\left(\mathrm{Ar}-\mathrm{H}_{2}(3 \%\right.$ vol. $\left.)\right)$. The surface area of supported catalysts after the same treatment decreased further to about $180 \mathrm{~m}^{2} \mathrm{~g}^{-1}$ on $\mathrm{NiCo}_{17}$ samples and to about $110 \mathrm{~m}^{2} \mathrm{~g}^{-1}$ on $\mathrm{NiCO}_{30}$ ones, showing that samples surface morphology is measurably affected by the addition of increasing amount of nickel and cobalt. Differently, the calcination temperature of the catalyst oxidic precursor more mildly affects the catalyst surface area. The same effect is observed for pore volume that was $0.80 \mathrm{~cm}^{3} \mathrm{~g}^{-1}$ for thermally treated alumina and decreased by metal addition to about 0.58 $\mathrm{cm}^{3} \mathrm{~g}^{-1}$ on all $\mathrm{NiCo}_{17}$ samples and $0.54 \mathrm{~cm}^{3} \mathrm{~g}^{-1}$ on $\mathrm{NiCO}_{30}$. Introduction of metal content in the substrate resulted in the reduction of the measured adsorbed volume in the pores, indicating blockage of pores mouth. Such values are still considered appropriate for a catalyst.

XRD patterns for the sample batch with metal loading 17 wt\% calcined at $450{ }^{\circ} \mathrm{C}, 600{ }^{\circ} \mathrm{C}$ and $750{ }^{\circ} \mathrm{C}$ ( Fig. 3) showed, irrespective of the calcination temperature, the presence of diffraction peaks of alumina, nickel and cobalt oxides, and no peaks from metal aluminates. The same applies for samples with metal loading $30 \%$. The peaks of $\mathrm{Co}_{3} \mathrm{O}_{4}$ phase are well visible already at the lower calcination temperature, whereas those of $\mathrm{NiO}$ appeared well resolved only after calcination at $750{ }^{\circ} \mathrm{C}$, despite the higher relative amount of $\mathrm{Ni}$ in the sample. This fact suggests that $\mathrm{NiO}$ segregation on $\mathrm{Al}_{2} \mathrm{O}_{3}$ occurs to a

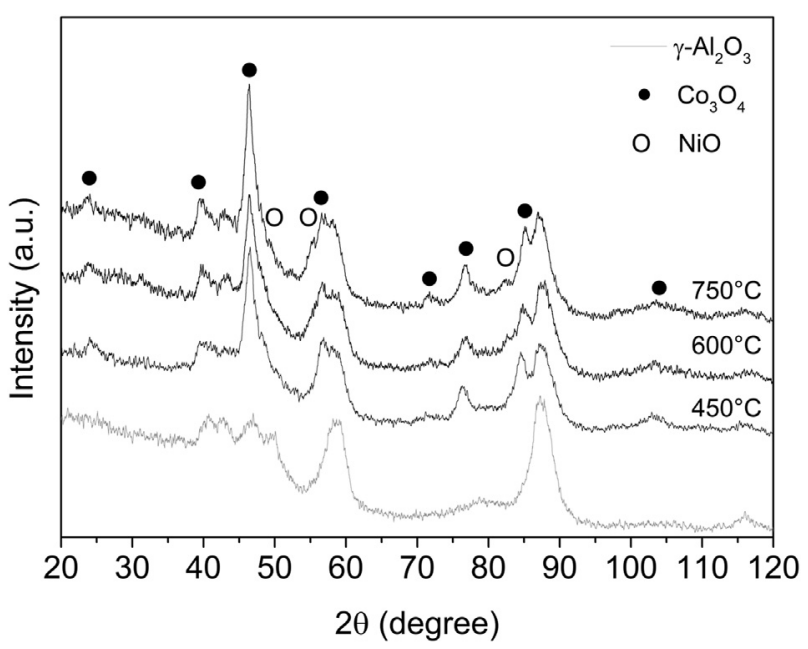

Fig.3 XRD patterns of samples calcined at three different temperatures: $450{ }^{\circ} \mathrm{C}, 600{ }^{\circ} \mathrm{C}$ and $750{ }^{\circ} \mathrm{C}$, metal loading $17 \%$, are reported together with pattern relative to bare alumina substrate. 


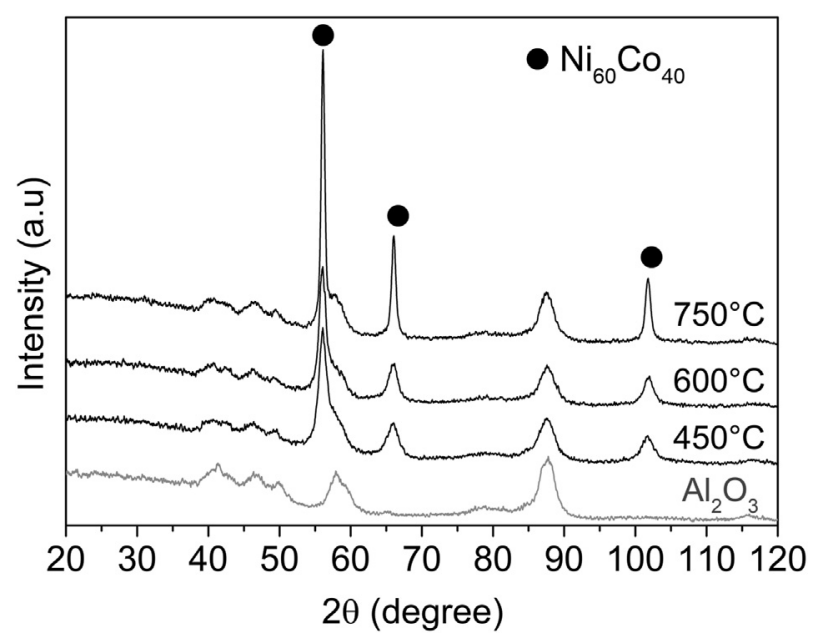

Fig. $4 \mathrm{XRD}$ patterns of the bare alumina substrate thermally treated at $900{ }^{\circ} \mathrm{C}$ for $5 \mathrm{~h}$ and of the samples calcined at $450{ }^{\circ} \mathrm{C}$, $600{ }^{\circ} \mathrm{C}$ and $750{ }^{\circ} \mathrm{C}$, after reduction at $900{ }^{\circ} \mathrm{C}$ for $5 \mathrm{~h}\left(\mathrm{NiCo}_{17} 450\right.$, $\mathrm{NiCo}_{17} 600$, and $\mathrm{NiCo}_{17} 750$ ). Sample metal loading $17 \%$. NieCo alloy is determined by comparison with ICCD-JCPDS database cards (\#4-850 and \#15-806).

lower extent with respect to Co-oxide species, possibly due to an interaction of $\mathrm{Ni}$ with $\mathrm{Al}_{2} \mathrm{O}_{3}$ surface stronger than that of Co. XRD patterns for the corresponding reduced samples are reported in Fig. 4 together with the diffraction profile of the bare support, which underwent the same thermal treatment $\left(900{ }^{\circ} \mathrm{C}, \mathrm{Ar}-\mathrm{H}_{2}, 5 \mathrm{~h}\right)$. The three samples show a very similar pattern profile, where, together with the substrate, only the peaks belonging to a single fcc metallic phase are visible, suggesting that the reduction reaction is complete. The cell parameter for the metallic phase is the same $\left(3.532(1){ }^{\circ} \mathrm{A}\right)$ for all the samples, an evidence of the same stoichiometry. Its value is in a good agreement with the one expected for an alloy $\mathrm{Ni}_{60} \mathrm{Co}_{40}$, for which the cell parameter linearly changes with the composition, from $3.5238^{\circ} \mathrm{A}$ for pure Ni fcc and $3.5447^{\circ}$ A for pure Co fcc [45]. The crystallite size of the metallic phase is calculated applying the Scherrer's equation on peak broad-ening and listed in Table 1. The crystallite size increases with the sample loading, aging time and calcination temperature, as expected [46]. At the same temperature, calcination in static atmosphere rather than flowing conditions produces larger particle size, possibly due to the presence of non-negligible water vapour pressure during the process $[47,48]$.

The TPR output results for the $\mathrm{NiCO}_{17}$ and $\mathrm{NiCO}_{30}$ samples calcined at different temperatures showed a different hydrogen consumption profile as a function of temperature (Fig. 5). As the reduction was not complete after reaching 900 ${ }^{\circ} \mathrm{C}$, an isotherm reduction for $5 \mathrm{~h}$ was required to obtain the complete reduction of oxides (total $\mathrm{H}_{2}$ consumption evaluated from the peak integrated area, $>99 \%$ ) and the stabilization of the support morphology. The peak at lower temperature is assigned to $\mathrm{CO}_{3} \mathrm{O}_{4}$ reduction to $\mathrm{CoO}$, as confirmed by XRD patterns performed on samples reduced at $350^{\circ} \mathrm{C}$ (not shown). The reduction of nickel oxide phase cannot be easily separated from the reduction of cobalt (II) oxide phase and a broad peak is detectable starting above

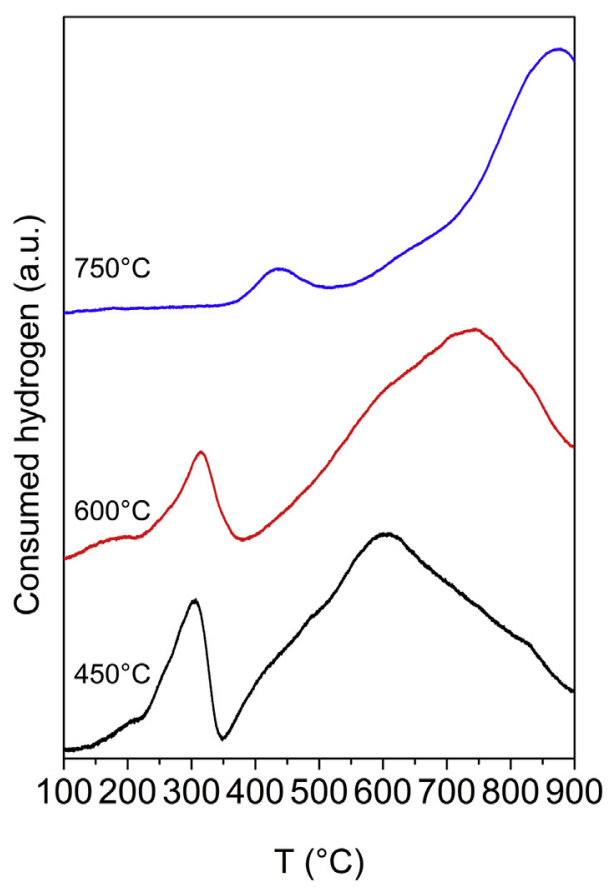

Fig.5 TPR profiles of samples calcined at $450{ }^{\circ} \mathrm{C}, 600{ }^{\circ} \mathrm{C}$ and 750 ${ }^{\circ} \mathrm{C}$ measured in in $\mathrm{AreH}_{2}$ (3\%vol.). Sample metal loading $17 \%$. Temperature scan rate $10^{\circ} \mathrm{C} \mathrm{m}$ i $\mathrm{n}^{\mathrm{i}}$.

$350{ }^{\circ} \mathrm{C}$ for samples calcined at $450^{\circ} \mathrm{C}$ and $600{ }^{\circ} \mathrm{C}$ and above 500 ${ }^{\circ} \mathrm{C}$ for the sample calcined at $750{ }^{\circ} \mathrm{C}$. The position of such broad reduction peak does not change significantly for the samples calcined at $600{ }^{\circ} \mathrm{C}$ and $750{ }^{\circ} \mathrm{C}$. We assume that the broad reaction peak represents the reduction of $\mathrm{Ni}$ (II) and Co(II) oxides to form a $\mathrm{Ni}_{60} \mathrm{Co}_{40}$ alloy. The $\mathrm{T}_{\max }$ of the broad peaks shifted towards higher temperature with increasing the calcination temperature of the sample, possibly due to a greater interaction of catalyst precursors with the support. The same trend was found for the $\mathrm{NiCO}_{30}$ samples at different calcination temperature.

The SEM images of all samples showed that the metal nanoparticles (light gray dots in the image due to their elemental composition different from the substrate) are evenly distributed within the porous alumina structure. In Fig. 6 the SEM images showing the morphology of two reduced samples $\mathrm{NiCo}_{17} 750$ (a) and $\mathrm{NiCo}_{30} 450 *$ (b) are re-ported. Particles size distribution histogram, included as an inset in the same figure, yielded the particle average diameter (Table 1) that are in line with crystallite size calculated form XRD data, an indication that metallic par-ticles are mostly single crystalline domain. The particles diameter and the corresponding spreading increase with metal loadings. Depending on the synthesis conditions, samples loaded at $17 \%$ show median diameters in the range 9-29 $\mathrm{nm}$ while for samples loaded at $30 \%$ the size distribution curve shifts to higher values, 18-52 $\mathrm{nm}$. Correspondingly, the width of the size distribution in-creases from 5 to $15 \mathrm{~nm}$, indicating that lower metal loading favors also a narrower size distribution. 


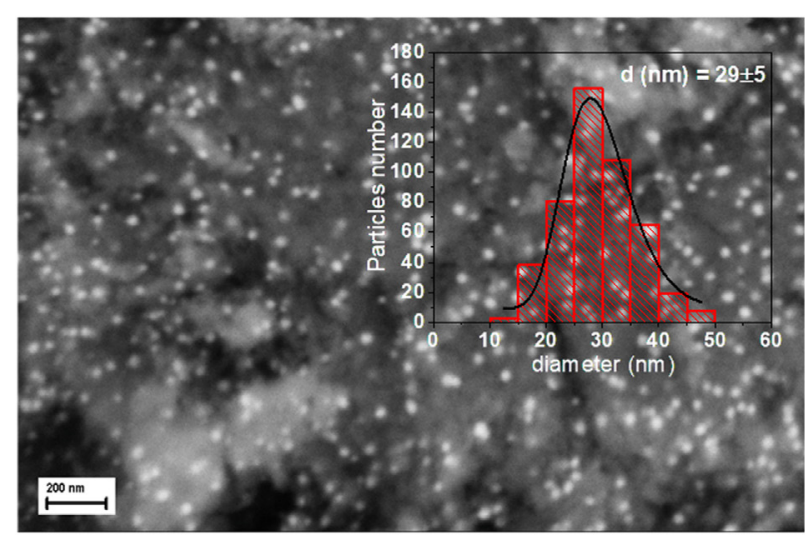

(a)

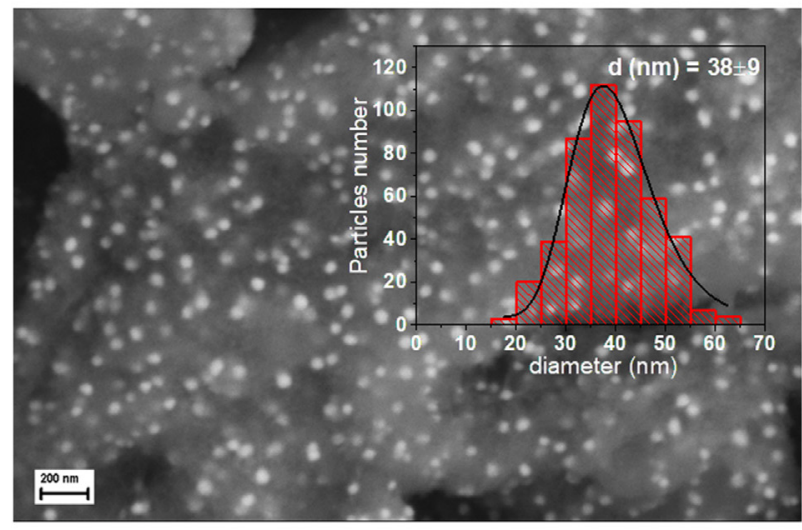

(b)

Fig.6 SEM images and size distribution histograms (top inset) of $\mathrm{Ni}_{60} \mathrm{Co}_{40}$ nanoparticles supported on $\mathrm{g}-\mathrm{Al}_{2} \mathrm{O}_{3}$ : (a) sample $\mathrm{NiCo}_{17} 750$ and (b) sample $\mathrm{NiCo}_{30} 450 *$.

Two additional SEM images are shown in Fig. 7. In Fig. $7 \mathrm{a}$ is reported an image at low magnification to highlight the ho-mogeneity of metal particle dispersion on the substrate, even for samples with high metal loading (30\%). In Fig. $7 \mathrm{~b}$ is shown an image relative to $\mathrm{NiCo}_{30} 600 * *$ whose particles have the biggest mean diameter obtained (Table 1). For this sample a static calcination (instead of the one in flow) was adopted during the preparation procedure. Even in this condition, that favored the growth of oxide particle size, it is possible to see that the metallic phase is well dispersed in isolated spherical particles, indicating a certain interaction alloy-support.

\section{Heating performances and catalytic activity}

The temperature reached in the catalytic bed under nitrogen

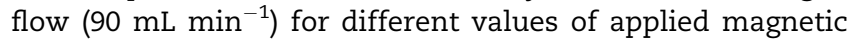
field is presented in Fig. 8 for $\mathrm{NiCo}_{30} 600$. Such trend is typical for all the samples, whereas the maximum temperature reached by each sample is different (Table 2) and depends on nanoparticles features. Indeed, as it will be later discussed, the heat generation rate can be governed by the amount of magnetic material loaded on the support and by the nanoparticles size. The temperature increases as the applied field increases up to a "saturation value", such that a further raise of the external field causes a negligible increase in

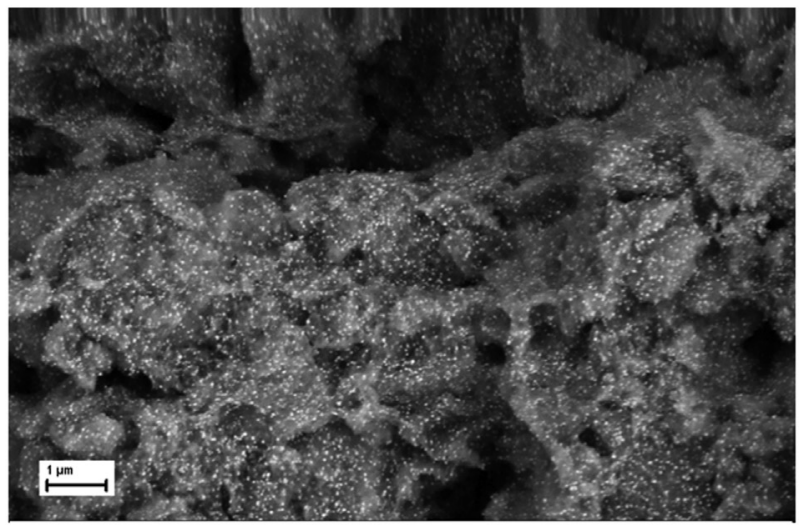

(a)

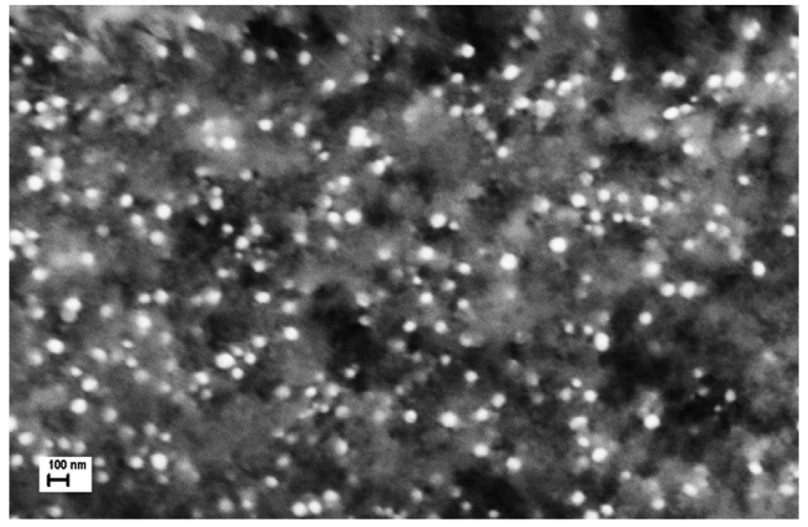

(b)

Fig.7 SEM images of two samples loaded at $30 \%$, calcined under different conditions. Section (a) $\mathrm{NiC}_{30} 600$. Section (b) $\mathrm{NiCo}_{30} 600^{* *}$ (static calcination).

temperature, at the expense of a considerable rise in power required to generate the field [23]. In the inset of Fig. 8 the variation of temperature as a function of time is recorded for a fixed input power. A steep increase in temperature is observed as soon as the field is switched on. After few minutes the observed temperature is the balance between heat dissipated by the nanoparticles and radiative and convective losses from the surface of the pellets. The heating system let to reach about $95 \%$ of the maximum temperature value in $2 \mathrm{~min}$. When the external field is removed the temperature rapidly drops down.

The NiCo catalysts heated by induction were active for the methane steam reforming reaction, reaching temperature in the range $490-620{ }^{\circ} \mathrm{C}$ and correspondent $\mathrm{CH}_{4}$ conversion in the range about 20 and $60 \%$ (Table 2). Measured values are in line with conversion data reported in the literature in this temperature range [49]. The effect of the flow rate over the methane conversion on the catalyst $\mathrm{NiCo}_{30} 600$ is reported in Fig. 9 keeping the applied input power constant, where essentially it appears that reactions are carried out in the kinetic regime.

Fig. 10a shows the composition of the outlet gas mixture for $\mathrm{NiCo}_{17} 600$ sample on a dry basis at the temperature reached by induction heating under reactant flow $\left(525^{\circ} \mathrm{C}\right)$. In all cases, the reaction temperature was slightly lower than 


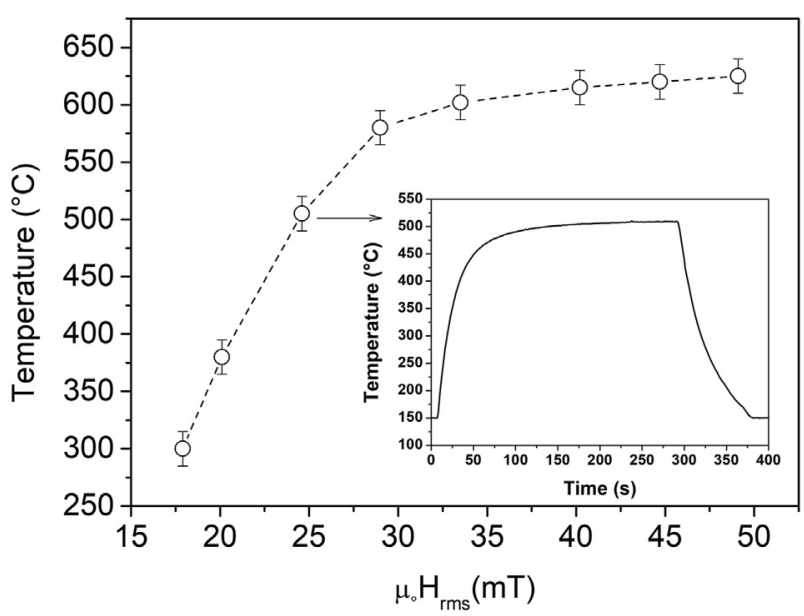

Fig.8 Temperature measured by the pyrometer focused on the catalytic bed external surface ( 18 pellets of $\mathrm{NiC}_{30} 600^{*}$ ) as a function of the magnetic field amplitude. The inset shows the heating profile at I $1 / 4110 \mathrm{~A}$,

B $1 / 424.6 \mathrm{mT}, \mathrm{H}^{1 / 4} 19.59 \mathrm{kA} \mathrm{m}{ }^{11}, \mathrm{~N}_{2}$ flow $1 / 490 \mathrm{~mL} \mathrm{~min}^{-1}$. Once the current passing through the inductor is switched off, the temperature rapidly drops demonstrating the advantage of a rapid on/off switching associated with induction heating.

that measured under $\mathrm{N}_{2}$ flow. In the present experiment, when the reactive mixture reaches the catalyst, the temperature decreases from $560{ }^{\circ} \mathrm{C}$ to about $525{ }^{\circ} \mathrm{C}$ due to contact with gas at a higher specific heat (water and methane compared to nitrogen) and also due to the absorbed heat of reaction (endothermic). As soon as methane and steam reach the catalyst, hydrogen and carbon monoxide are produced and their values rapidly reach a plateau. On the contrary, carbon dioxide is observed only after few minutes and increases with time-on-stream, reaching a plateau in $20 \mathrm{~min}$. The conversion of methane was around $35 \%$, in line with the equilibrium value corresponding at the measured temperature indicating the good activity of the catalyst [39]. The considerable amount of carbon dioxide observed is also in line with the measured temperature values. Actually, at this temperature, the water gas shift reaction is favored, and carbon dioxide and hydrogen are produced at expenses of carbon monoxide, whose quantity in the mixture is limited to $4 \%$ by volume.

For $\mathrm{NiCO}_{30}$ catalysts (high metal content) it is immediately evident that methane conversion and carbon monoxide amount are higher compared to those on samples with lower metal loading. This is certainly due to the higher values of temperature that catalysts reach compared to those of the $\mathrm{NiCO}_{17}$ series (see Table 2). Fig. 10b shows the conversion of methane and product distribution for the most performing sample $\left(\mathrm{NiCO}_{30} 450 *\right)$, for which the measured temperature is $665^{\circ} \mathrm{C}$ under nitrogen flow, and $618^{\circ} \mathrm{C}$ during the process. The measured methane conversion is the one expected at such temperature, indicating also for this high metal loading catalyst the good catalytic performance. These data showed
Table 2 Temperature on samples surface when heated by induction $\mathrm{T}_{\mathrm{N} 2}$, and during the reforming reaction, $\mathrm{T}_{\text {reac }}$; methane conversion, $\mathrm{X}_{\mathrm{CH} 4}$, and catalyst reaction rate. Data measured on 18 pellets of catalyst.

\begin{tabular}{lcccc} 
Sample & $\mathrm{T}_{\mathrm{N} 2}\left({ }^{\circ} \mathrm{C}\right)^{\mathrm{a}} \mathrm{T}_{\text {reac }}\left({ }^{\circ} \mathrm{C}\right)^{\mathrm{a}, \mathrm{b}} \mathrm{X}_{\mathrm{CH} 4}(\%)$ & $\begin{array}{c}\text { Reaction rate } \\
\left(\mathrm{Mol}_{\mathrm{CH} 4} \mathrm{~g}_{\mathrm{Me}}^{-1} \mathrm{~h}^{-1}\right)\end{array}$ \\
\hline $\mathrm{NiCo}_{17} 450$ & 520 & 490 & 19 & 0.40 \\
$\mathrm{NiCo}_{17} 600$ & 560 & 525 & 36 & 0.74 \\
$\mathrm{NiCo}_{17} 600 *$ & 575 & 550 & 44 & 0.93 \\
$\mathrm{NiCo}_{17} 750$ & 570 & 535 & 38 & 0.80 \\
$\mathrm{NiCo}_{17} 750 *$ & 536 & 510 & 33 & 0.69 \\
$\mathrm{NiCo}_{30} 450 *$ & 665 & 618 & 60 & 0.58 \\
$\mathrm{NiC}_{30} 600$ & 570 & 530 & 45 & 0.45 \\
$\mathrm{NiCo}_{30} 600 *$ & 630 & 600 & 56 & 0.55 \\
$\mathrm{NiCo}_{30} 600 * *$ & 415 & 400 & 15 & 0.15 \\
$\mathrm{NiCo}_{30} 750$ & 625 & 605 & 48 & 0.50
\end{tabular}

${ }^{\text {a }}$ Heating parameters: $\mathrm{I}=220 \mathrm{~A}, \mathrm{~B}=49.1 \mathrm{mT}, \mathrm{H}=39.19 \mathrm{kAm}^{-1}$ $\mathrm{P}=0.9 \mathrm{~kW}$ in nitrogen flow $\left(\mathrm{N}_{2}=90 \mathrm{~mL} \mathrm{~min}^{-1}\right)$. The estimated error was $\pm 10^{\circ} \mathrm{C}$ due to difficulties in focusing the IR pyrometer on the pellets external surface.

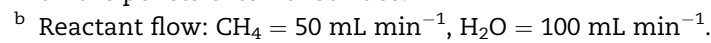

c Calculated from the amount (moles) of methane converted.

that, under the same magnetic field condition, a higher metal loading favors the attainment of higher temperatures, as the number of dissipating agents increases.

The capability of magnetic nanoparticles to dissipate energy in an alternating magnetic field, usually reported as Specific Power Loss (SPL i.e. the amount of heat generated per unit gram of magnetic material and per unit time) depends on several parameters [3,27,50-53]. Essentially, the ability of magnetic nanoparticles to act as heat mediators is affected by their composition, structural, morphological and magnetic properties (intrinsic parameters directly dependent on the sample preparation method) and the amplitudes and frequency of the applied field (extrinsic parameters), not straightforward predictable because of several mechanisms

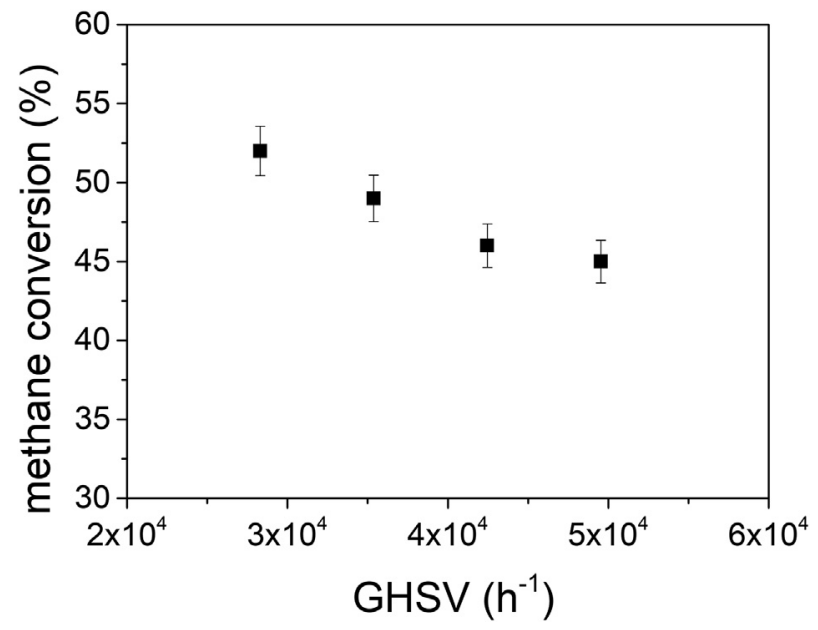

Fig.9 Percent methane conversion as a function of the gas hourly space velocity $\left(\mathrm{h}^{{ }^{11}}\right)$ defined as the ratio of the volumetric feed flow rate (normal condition) to the volume of the catalyst bed, geometrically determined. Sample $\mathrm{NiC}_{30} 600$. 

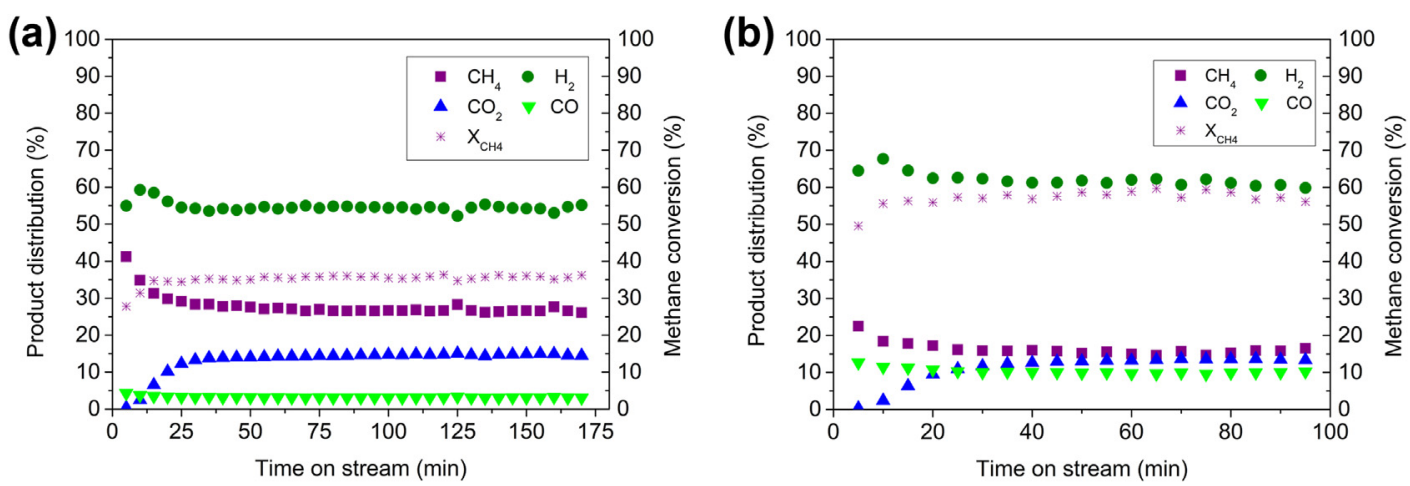

Fig.10 Composition of the outlet mixture and methane conversion at the reaction temperature $\left(\mathrm{T}_{\text {reac }}\right)$ reached upon radiofrequency heating. Section (a) sample $\mathrm{NiCo}_{17} 600\left(\mathrm{~T}_{\text {reac }}{ }^{1 / 4} 525^{\circ} \mathrm{C}\right)$; section (b) $\mathrm{NiCo}_{30} 450^{*}\left(\mathrm{~T}_{\text {reac }} 1 / 4618^{\circ} \mathrm{C}\right)$. Applied magnetic field $49.1 \mathrm{mT}, \mathrm{I} 1 / 4$ 220 A. Volumetric inlet flow: $\mathrm{N}_{2} 1 / 490 \mathrm{~mL} \mathrm{~min}^{-1}, \mathrm{C} \mathrm{H}_{4} 1 / 450 \mathrm{~mL} \mathrm{~min}^{-1}, \mathrm{H}_{2} \mathrm{O} 1 / 4100 \mathrm{~mL} \mathrm{~min}^{-1},\left(\mathrm{GHSV} 1 / 428,310 \mathrm{~h}^{\mathrm{i}}\right)$.

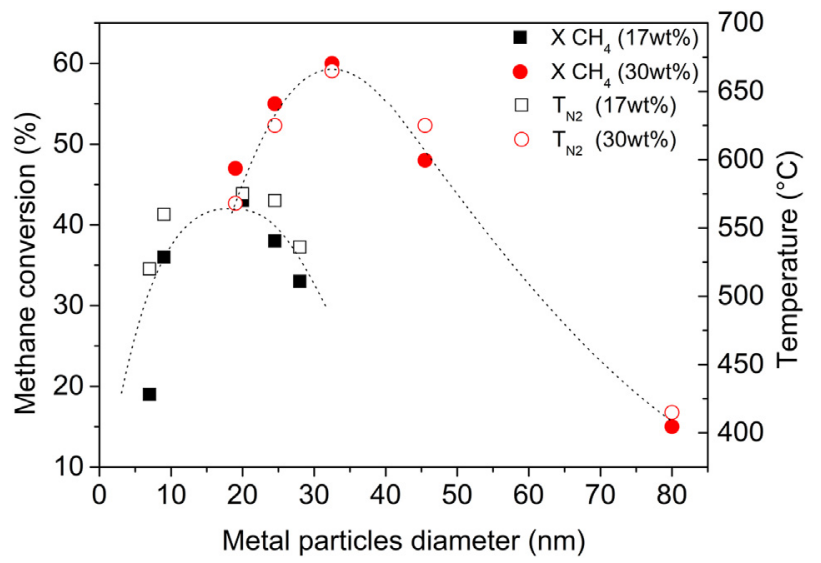

Fig.11 The measured methane conversion as a function of $\mathrm{Ni}_{60} \mathrm{Co}_{40}$ alloy particle diameter. In the same picture the temperature measured on the sample surface $\left(T_{\mathrm{N} 2}\right)$, which accounts for the sample ability to dissipate energy under nitrogen flow $(90 \mathrm{~mL} \mathrm{~min}-1$ ) is reported. The dotted line is a guide for the eye.

contributing to magnetic losses. Experimental work is therefore often required in view of materials optimization. An attempt to rationalize the results is shown in Fig. 11 reporting for all the samples the methane conversion and the temperature reached on the sample surface in nitrogen flow, $\mathrm{T}_{\mathrm{N} 2}$, as a function of the $\mathrm{Ni}_{60} \mathrm{Co}_{40}$ particle diameter. All measurements were carried out keeping constant the number of catalyst pellets in the reactor, the gas flow and the applied magnetic field (frequency and amplitude). The data were grouped ac-cording to the sample metal loading. It is evident a strong dependence of $\mathrm{T}_{\mathrm{N} 2}$ (and therefore of the conversion of methane which directly depends on it) on the size of the nanoparticles. Considering the samples with lower loading, it can be observed how for particles smaller than $20 \mathrm{~nm} \mathrm{~T}_{\mathrm{N} 2}$ increases as the size increases and then descends as the latter increases. The same profile can be observed for samples with higher loading, with the difference that the maximum of the curve is shifted to $30-35 \mathrm{~nm}$. These temperature profiles follow the dependence of the Specific Power Loss on particles size, which has been modeled by Hergt [48] for magnetic iron oxide nanoparticles for hyperthermia. Such profile is the result of different magnetic loss mechanisms intervening in the heat dissipation. It is known $[2,4,5,48,54]$ that hysteresis loss and relaxation loss are the two major power loss mechanisms of magnetic induction heating and that exists a critical particle size below which relaxation loss dominates, or else the hysteresis loss prevails. Then, in induction heated catalytic processes, in order to enhance the heat dissipation efficiency of the sample, it is of great importance the control of synthesis process to obtain particles with optimal diameter. As can be seen in Table 2, for samples loaded with the same amount of metal (30\%), a very wide range of the $\mathrm{T}_{\mathrm{N} 2}$ reached by induction heating $\left(200^{\circ} \mathrm{C}\right)$ was measured, indicating very different dissipation ability for materials with the same nominal composition. For application purposes, the use of a sample such as $\mathrm{NiCO}_{30} 600 * *$ would be highly inefficient.

What is unexpected is that the trend curve drawn for the set of samples loaded at $30 \%$ has its maximum moved to slightly larger size when instead we would have expected, given the same chemical composition of the particles, that the two curves showed a parallel trend. It is probable that the effect of a wider distribution of particle size for samples with $30 \%$ metal content, compared to samples with $17 \%$ is such that moves the curve toward larger dimensions [2]. Magnetic interaction among nanoparticles can also be taken in consideration as a possible cause. In order to uniquely assess the cause of such shift a detailed magnetic characterization, beyond the scope of the present work, is needed.

To further clarify the role of particle size in determining the observed catalytic behavior we compare for all catalysts the rate of $\mathrm{CH}_{4}$ converted per gram of metal in the catalyst (mol $\mathrm{mH}_{4}$ $\mathrm{g}^{-} \mathrm{Me}^{1} \mathrm{~h}^{-1}$ ) whose values for dilute $\mathrm{NiCo}_{17}$ samples are almost all higher than those for concentrated $\mathrm{NiCO}_{30}$ samples (Table 2). Particles with similar size $(\sim 20 \mathrm{~nm}) \mathrm{NiCo}_{17} 600 *$ and $\mathrm{NiC}_{30} 600$ yield the same $\mathrm{T}_{\mathrm{N} 2}$ but different rate, higher on dilute catalyst where they are in a lower amount. This suggests a different nature of the exposed surface in concentrated samples. However, samples with the same metal content but having particles with different mean diameter (i.e. different exposed metal surface values) yield similar $\mathrm{T}_{\mathrm{N} 2}$ and similar $\mathrm{CH}_{4}$ 

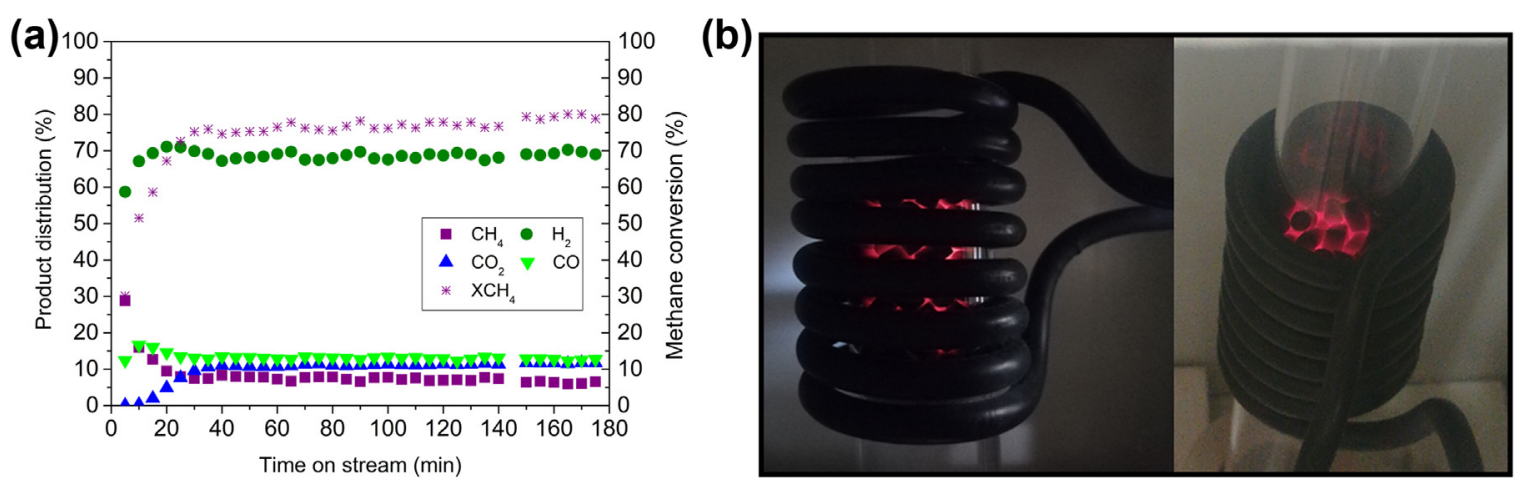

Fig. 12 (a) Experimental product distribution and methane conversion values for sample $\mathrm{NiCo}_{30} 600$. Volumetric inlet flow: $\mathrm{N}_{2} 1 / 490 \mathrm{~mL}$ $\mathrm{min}^{-1}, \mathrm{CH}_{4} 1 / 450 \mathrm{~mL} \mathrm{~min}^{-1}, \mathrm{H}_{2} \mathrm{O} 1 / 4100 \mathrm{~mL} \mathrm{~min}^{-1}$. GHSV $1 / 42800 \mathrm{~h}^{\mathrm{i} 1}$. $\mathrm{T}_{\text {reac }} 1 / 4720{ }^{\circ} \mathrm{C}$. Section (b): a digital photograph of the $\mathrm{NiCo}_{30} 600$ catalysts heated by induction at work (180 pellets housed in the quartz reactor placed inside the coil). The current applied to the coil was I $1 / 4$ $220 \mathrm{~A}$.

conversions and rates (see Table 2 and Fig. 11, samples $\mathrm{NiCo}_{17} 600$ and $\mathrm{NiCo}_{17} 750 *$ ). These results suggest that the dependence of the reaction rate on the exposed metal surface value affects the reaction rate less than temperature values.

In the experiments reported so far, approximately $0.5 \mathrm{~g}$ of catalysts (18 pellets) have been used which occupy a geometric volume equal to $0.5 \mathrm{~mL}$. Such volume it is only a small fraction of inductor volume $(\approx 20 \mathrm{~mL})$ and indeed the power delivered to the inductor does not change appreciably when the magnetic catalyst is placed inside. In this configuration, the best result in terms of methane conversion $\left(\mathrm{X}_{\mathrm{CH} 4}=60 \%\right.$, when $\mathrm{T}_{\mathrm{N} 2}$ was $665^{\circ} \mathrm{C}$, see Table 2) has been obtained with the $\mathrm{NiCO}_{30} 450 *$ sample that shows a catalyst productivity in the range $0.17-0.25 \mathrm{~mol}_{\mathrm{CH} 4} \mathrm{~g}_{\text {cat }}^{-} \mathrm{h}^{-1}$ depending on the methane flowrate conveyed to the reactor. The reaction rate was calculated considering the moles per hour of methane converted during the process over the total mass of the supported catalyst $\left(\mathrm{Al}_{2} \mathrm{O}_{3}-\mathrm{Ni}_{60} \mathrm{Co}_{40}\right)$. The reaction rate rises to $0.58-0.84$ $\mathrm{mol} \mathrm{h}{ }^{-1} \mathrm{~g}^{-} \mathrm{Me}^{1}$ considering the amount of the metal only, as reported in Table 2 .

In order to better exploit the magnetic field generated inside the inductor, the reactor was loaded with a greater amount of catalyst (180 pellets of $\mathrm{NiCO}_{30} 600$, volume occupied in reactor $\approx 10 \mathrm{~mL}$, central part of the coil). Results are reported in Fig. 12 together with images of the reactor in operation. $\mathrm{T}_{\mathrm{N} 2}$ value rises from $630^{\circ} \mathrm{C}$, obtained using 18 pellets of catalyst, to $740{ }^{\circ} \mathrm{C}$, obtained with 180 pellets, because a greater number of pellets participate in the dissipative process. It is therefore expected that at this thermal level the conversion of methane to carbon monoxide and hydrogen is higher than what has been seen so far. Indeed, the measured methane conversion reaches $80 \%$ and the amount of carbon dioxide further decreases, since the reaction of water gas shift is less favored at this temperature $\left(\mathrm{H}_{2} / \mathrm{CO}\right.$ ratio $\left.~ 6\right)$. At the same time, the input power needed to generate the magnetic field (49.1 $\mathrm{mT}$ ) increases from $900 \mathrm{~W}$ (empty coil) to $970 \mathrm{~W}$. In the reported experimental conditions, the energy transfer efficiency is around $1.75 \%$. The main factors influencing this value are related to our specific experimental set-up, which is not optimized. As previously discussed, when the quantity of catalyst has been increased ten times, the temperature on the catalyst surface increases considerably due to minimization of thermal losses, leading to an increase of the conversion value. At the same time, due to instrumental set-up limitations, it was not possible to increase the flow of reagent sent the catalyst and the catalytic activity remains low, the process being limited by diffusional reasons. By a simple approximation, using the same GHSV of the previous experiments the efficiency would raise to $16 \%$. An optimization of the catalyst test plant from an engineering point of view will certainly provide higher efficiency values [22].

Finally, initial stability tests have shown that the catalyst is stable in several successive work cycles showing conversion values equal to the initial one, an encouraging detail in view of long-term stability tests.

\section{Conclusion}

The progress in the design and development of materials for magnetic catalysis has the potential to allow the implementation of highly energy-intensive processes on smallscale, compact reactors, thanks to the rapid and targeted response of ferromagnetic nanoparticles to an applied magnetic field. Ferromagnetic $\mathrm{Ni}_{60} \mathrm{Co}_{40}$ nanoparticles supported on commercial $\gamma-\mathrm{Al}_{2} \mathrm{O}_{3}$ pellets proved to be active for the steam methane reforming reaction, when inductively heated by a radiofrequency alternating magnetic field, demonstrating their dual function as heat dissipating agent and active catalyst for the chemical process. Despite the high metal loading of the synthesized catalysts (17\% and $30 \%), \mathrm{Ni}_{60} \mathrm{Co}_{40}$ nanoparticles are well dispersed on the support, suggesting that the selected synthetic methodology, easily scalable to mass production, is appropriate. In concentrated catalysts the higher concentration of dissipating agent maximizes the productivity per mass of catalyst; in dilute catalysts the presence of small nanoparticles maximizes activity per metal site. The measured methane conversion values give indication of an important and peculiar dependence on the metal particle size distribution that reflects the ability of the nanoparticles to dissipate energy into heat upon the application of the magnetic field. Indeed, the size of the metal particles is a critical 
key factor to obtain a higher heating rate and an efficient conversion of magnetic energy into heat, essential to maximize the overall catalyst performance. This finding is particularly relevant for high temperature endothermic reactions in which the effectiveness of heat transfer is a fundamental parameter in defining the efficiency of the process. Optimization of synthesis parameters is therefore of utmost importance to obtain nanoparticles with fine-tuned features in terms of dissipating agents and active surface. Some of the materials designed and produced achieve methane conversions close the target value; efficiency must be improved optimizing operative parameters of reforming reaction functional tests.

\section{Declaration of competing interest}

The authors declare that they have no known competing financial interest or personal relationships that could have appeared to influence the work reported in this paper.

\section{Acknowledgement}

This work has been conducted within the framework of the "Accordo di Programma Ministero dello Sviluppo EconomicoENEA", Project D3: Efficienza energetica nel settore industria.

\section{references}

[1] Stoner EC, Wohlfarth EP. A mechanism of magnetic hysteresis in heterogeneous alloys. Phil Trans Roy Soc Lond 1948;240:599-642. https://doi.org/10.1098/rsta.1948.0007.

[2] P'erigo EA, Hemery G, Sandre O, Ortega D, Garaio E, Plazaola F, Teran FJ. Fundamentals and advances in magnetic hyperthermia. Appl Phys Rev 2015;2:041302. https://doi.org/10.1063/1.4935688. 35.

[3] Shaterabadi Z, Nabiyouni G, Soleymani M. Physics responsible for heating efficiency and self-controlled temperature rise of magnetic nanoparticles in magnetic hyperthermia therapy. Prog Biophys Mol Biol 2018;133:9-19. https://doi.org/10.1016/j.pbiomolbio.2017.10.001.

[4] Dennis CL, Ivkov R. Physics of heat generation usingmagneticnanoparticles for hyperthermia. Int J Hyperther 2013;29:715-29. https://doi.org/10.3109/ 02656736.2013 .836758

[5] Houlding TK, Rebrov EV. Application of alternative energy forms in catalyticreactor engineering. Green Process Synth 2012;1:19-31. https://doi.org/10.1515/greenps-2011-0502.

[6] Kirschning A, Kupracz L, Hartwig J. New synthetic opportunities in miniaturized flow reactors with inductive heating. Chem Lett 2012;41:562-70. https://doi.org/10.1246/ cl.2012.562.

[7] Meffre A, Mehdaoui B, Connord V, Carrey J, Fazzini PF, Lachaize S, Respaud M, Chaudret B. Complex nano-objects displaying both magnetic and catalytic properties: a proof of concept for magnetically induced heterogeneous catalysis. Nano Lett 2015;15:3241-8. https://doi.org/10.1021/ acs.nanolett.5b00446.

[8] Mortensen PM, Engbæk JS, Vendelbo SB, Hansen MF, $\emptyset$ stberg M. Direct hysteresis heating of catalytically active $\mathrm{Ni}-\mathrm{Co}$ nanoparticles as steam reforming catalyst. Ind Eng
Chem Res 2017;56:14006-13. https://doi.org/10.1021/ acs.iecr.7b02331.

[9] Vinum MG, Almind MR, Engbaek JS, Vendelbo SB, Hansen MF, Frandsen K, Bendix J, Mortensen PM. Dualfunction cobalt-nickel nanoparticles tailored for hightemperature induction-heated steam methane reforming. AngewChemInt Ed Engl 2018;57:10569-73. https://doi.org/ 10.1002/anie.201804832.

[10] Wang W, Tuci G, Duong-Viet C, Liu Y, Rossin A, Luconi L, Nhut J-M, Nguyen-Dinh L, Pham-Huu C, Giambastiani G. Induction heating: an enabling technology for the heat management in catalytic processes. ACS Catal 2019;9:7921-35. https://doi.org/10.1021/acscatal.9b02471.

[11] Asensio JM, Miguel AB, Fazzini PF, van Leeuwen PWNM, Chaudret B. Hydrodeoxygenation using magnetic induction: high-temperature heterogeneous catalysis in solution. Angew ChemInt Ed 2019;58:11306-10. https://doi.org/ 10.1002/anie.201904366.

[12] de la Hoz A, Díaz- Ortiz A. Sustainable flow chemistry: methods and applications, chapter 9, nonconventional techniques in sustainable flow chemistry. WILEY-VCH Verlag GmbH \& Co. KGaA; 2017.

[13] Nguyen HM, Pham GH, Ran R, Vagnoni R, Pareek V, Liu S. Dry reforming of methane over $\mathrm{Co}-\mathrm{Mo} / \mathrm{Al} 2 \mathrm{O} 3$ catalyst under low microwave power irradiation. Catal. Sci. Technol. 2018;8:5315-24. https://doi.org/10.1039/c8cy01601a.

[14] Zadra 'zil A, 'St '̌ep'anek F. Remote control of reaction rate by radiofrequency heating of composite catalyst pellets. Chem Eng Sci 2015;134:721-6. https://doi.org/10.1016/ j.ces.2015.05.055.

[15] Hamzehlouia S, Jaffer SA, Chaouki J. Assisted catalytic dry reforming of methane to syngas. Sci Rep 2018;8:8940-7. https://doi.org/10.1038/s41598-018-27381-6.

[16] Hartwig J, Ceylan S, Kupracz L, Coutable L, Kirschning A. Heating under high-frequency inductive conditions: application to the continuous synthesis of the neurolepticum olanzapine (zyprexa). Angew Chem Int Ed 2013;52:9813-7. https://doi.org/10.1002/anie.201302239.

[17] Hamzehlouia S, Shabanian J, Latifi M, Chaouki J. Effect of microwave heating on the performance of catalytic oxidation of n-butane in a gas-solid fluidized bed reactor. Chem Eng Sci 2018;192:1177-88. https://doi.org/10.1016/ j.ces.2018.08.054.

[18] P'erez-Camacho MN, Abu-Darieh J, Rooney D, Sun K. Biogas reforming using renewable wind energy and induction heating. Cataysis Today 2015;242:129-38. https://doi.org/ 10.1016/j.cattod.2014.06.010.

[19] Haneishi N, Tsubaki S, Abe E, Maitani MM, Suzuki E, Fujii S, Fukushima J, Takizawa H, Wada Y. Enhancement of fixed-bed flow reactions under microwave irradiation by local heating at the vicinal contact points of catalyst particles. Sci Rep 2019;9:222-34. https://doi: 10.1038/s41598-018-35988-y.

[20] Hart A, Adam M, Robinson JP, Rigby SP, Wood J. Hydrogenation and dehydrogenation of tetralin and naphthalene to explore heavy oil upgrading using NiMo/ $\mathrm{Al} 2 \mathrm{O} 3$ and CoMo/Al2O3 catalysts heated with steel balls via induction. Catalysts 2020;10:497-515. https://doi.org/ 10.3390/catal10050497.

[21] E. Meloni, M. Martino, A. Ricca, V. Palma, Ultracompact methane steam reforming reactor based on microwaves susceptible structured catalysts for distributed hydrogen production, Int J Hydrogen Energy 2020. https://doi.org/10. 1016/j.ijhydene.2020.06.299.

[22] Almind MR, Vendelbo SB, Hansen MF, Vinum MG, Frandesn G, Mortensen PM, Engbaek JS. Improving performance of induction-heated steam methane reforming. Catal Today 2020;342:13-20. https://doi.org/10.1016/ j.cattod.2019.05.005. 
[23] Varsano F, Bellusci M, Provino A, Petrecca M. NiCo as catalyst for magnetically induced dry reforming of methane. Mater Sci Eng 2018;323:012005. 11, https://doi:10.1088/1757-899X/ 323/1/012005.

[24] Varsano F, Bellusci M, La Barbera A, Petrecca M, Albino M, Sangregorio C. Dry reforming of methane powered by magnetic induction. Int J Hydrogen Energy 2019;44:21037-44. https://doi.org/10.1016/j.ijhydene.2019.02.055.

[25] Akbarzadeh A, Samiei M, Davaran S. Magnetic nanoparticles: preparation, physical properties, and applications in biomedicine. Nanoscale Res Lett 2012;7:144-57. https:// doi.org/10.1186/1556-276X-7-144.

[26] Ma M, Wu Y, Zhou J, Sun Y, Zhang Y, Gu N. Size dependence of specific power absorption of $\mathrm{Fe} 3 \mathrm{O} 4$ particles in AC magnetic field. J Magn Mater 2004;268:33-9. https://doi.org/ 10.1016/S0304-8853(03)00426-8.

[27] Garaio E, Sandre O, Collantes J, Garcia JA, Mornet S, Plazola F. Specific absorption rate dependence on temperature in magnetic field hyperthermia measured by dynamic hysteresis losses (ac magnetometry). Nanotechnology 2015;26:015704. https://doi.org/10.1088/0957-4484/26/1/ 015704. 22

[28] Navarro RM, Pe na MA, Fierro JLG. Hydrogen production reactions from carbon feedstocks: fossil fuels and biomass. Chem Rev 2007;107:3952-91. https://doi.org/10.1021/ cr0501994.

[29] Wei Z, Sun J, Li Y, Datye AK, Wang Y. Bimetallic catalysts for hydrogen generation. Chem Soc Rev 2012;41:7994-8008. https://doi.org/10.1039/C2CS35201J.

[30] Nguyen LQ Abella L, Gallardo S, Hinode H. Effect of nickel loading on the activity of $\mathrm{Ni} / \mathrm{ZrO} 2$ for methane steam reforming at low temperature. React Kinet Catal Lett 2008;93:227-32. https://doi.org/10.1007/s11144-008-5253-2.

[31] LeValley TL, Richard AR, Fan M. The progress in water gas shift and steam reforming hydrogen production technologies - a review. Int J Hydrogen Energy 2014;39:16983-7000. https://doi.org/10.1016/j.ijhydene.2014.08.041.

[32] Nazari M, Mehdi Alavi S. An investigation of the simultaneous presence of $\mathrm{Cu}$ and $\mathrm{Zn}$ in different Ni/Al2O3 catalyst loads using Taguchi design of experiment in steam reforming of methane. Int J Hydrogen Energy 2020;45:691-702. https://doi.org/10.1016/ j.ijhydene.2019.10.224

[33] Wisman ST, Engbæk JS, Vendelbo SB, Bendixen FB, Eriksen WL, Aasberg-Petersen K, et al. Electrified methane reforming, a compact approach to greener industrial hydrogen production. Science 2019;364:756-9. https:// doi.org/10.1126/science.aaw8775.

[34] Meloni E, Martino M, Palma V. A short review on Ni based catalysts and related engineering issues for methane steam reforming. Catalysts 2020;10:352-90. https://doi.org/10.3390/ catal10030352.

[35] Yun J, Kim Y, Yu S. Interactive heat transfer characteristics of $5 \mathrm{~kW}$ class shell-and-tube methane steam reformer with intermediate temperature heat source. Int J Hydrogen Energy 2020;45:21767-78. https://doi.org/10.1016/ j.ijhydene.2020.05.152.

[36] Peng XD. Analysis of the thermal efficiency limit of the steam methane reforming process. Ind Eng Chem Res 2012;51:16385-92. https://doi.org/10.1021/ie3002843.

[37] Ataloglou T, Fountzoula C, Bourikas K, Vakros J, Lycourghiotis A, Kordulis C. Cobalt oxide/g-alumina catalysts prepared by equilibrium deposition filtration: The influence of the initial cobalt concentration on the structure of the oxide phase and the activity for complete benzene oxidation. Appl Catal Gen 2005;288:1-9. https://doi.org/ 10.1016/j.apcata.2004.11.022.

[38] Schneider CA, Rasband WS, Eliceiri KW. NIH Image to ImageJ: 25 years of image analysis. Nat Methods 2012;9:671-5. https://doi.org/10.1038/nmeth.2089.

[39] Brunauer Stephen, Emmet PH, Teller Edward. The adsorption of gases in multimolecular layers. J Am Chem Soc 1938;60:309-19. https://doi.org/10.1021/ja01269a023.

[40] HSC chemistry software ver. 6.1, Outotec Technologies, https://www.hsc-chemistry.com/

[41] Binary alloy phase diagrams. In: Massalski TB, editor. American society for metals, metals park, Ohio, 1; 1986. p. 44073.

[42] You X, Wang X, Ma Y, Liu J, Liu W, Xu X, Peng H, Li C, Zhou W, Yuan P, Chen X. Ni-Co/Al2O3 bimetallic catalysts for $\mathrm{CH} 4$ steam reforming: elucidating the role of Co for improving coke resistance. ChemCatChem 2014;6:3377-86. https://doi.org/10.1002/cctc.20140265.

[43] Harshini D, Kwon Y, Han J, Yoon S, Nam S, Lim T-H. Suppression of carbon formation in steam reforming of methane by addition of Co into Ni/ZrO2 catalysts. Kor J Chem Eng 2010;27:480-6. https://doi.org/10.1007/s11814-010-0095-9.

[44] Barrett EP, Joyner LG, Halenda PP. The determination of pore volume and area distributions in porous substances. 1. Computation from nitrogen isotherms. J Am Chem Soc 1951;73:373-80. https://doi.org/10.1021/ja01145a126.

[45] PDF-2 Database: International Centre for Diffraction Data (ICDD). https://www.icdd.com/

[46] Vos B, Poels E, Bliek A. Impact of calcination conditions on the structure of alumina-supported nickel particles. J Catal 2001;198:77-88. https://doi.org/10.1006/jcat.2000.3082.

[47] Sehested J, Gelten JAP, Remediakis IN, Bengaard H, Nørskovb JK. Sintering of nickel steam-reforming catalysts: effects of temperature and steam and hydrogen pressures. J Catal 2004;223:432-43. https://doi.org/10.1016/ j.jcat.2004.01.026.

[48] Bartholomew $\mathrm{CH}$. Mechanisms of catalyst deactivation. Appl Catal, A 2001;212:17-60. https://doi.org/10.1016/S0926860X(00)00843-7.

[49] Angeli SD, Monteleone G, Giaconia A, Lemonidou AA. Stateof-the-art catalysts for $\mathrm{CH} 4$ steam reforming at low temperature. Int J Hydrogen Energy 2014;39:1979-97. https:// doi.org/10.1016/j.ijhydene.2013.12.001.

[50] Tong S, Quinto CA, Zhang L, Mohindra P, Bao G. Sizedependent heating of magnetic iron oxide nanoparticles. ACS Nano 2017;11:6808-16. https://doi.org/10.1021/ acsnano.7b01762.

[51] Cotin G, Perton F, Blanco-Andujar C, Pichon B, Mertz D, $B$ 'egin S. Nanomaterials for magnetic and optical hyperthermia applications. chapter 2 p41-60. Elsevier; 2018, ISBN 9780128139288.

[52] Hergt R, Roder S Dutzand M. Effects of size distribution on hysteresis losses of magnetic nanoparticles for hyperthermia. J Phys: Condens Matter 2008;20:385214-26. https://doi.org/10.1088/0953-8984/20/38/385214.

[53] Lemal P, Geers C, Rothen-Rutishauser B, Lattuada M, PetriFink A. Measuring the heating power of magnetic nanoparticles: an overview of currently used methods. Mater Today Proc 2017;4:S107-17. https://doi.org/10.1016/ j.matpr.2017.09.175.

[54] Mehdaoui B, Meffre A, Carrey J, Lachaize S, Lacroix L-M, Gougeon M, Respaud M. Optimal Size of Nanoparticles for magnetic Hypertermia: a combined theoretical and experimental study. Adv Funct Mater 2011;21:4573-81. https://doi.org/10.1002/adfm.201101243. 